\title{
Assessment of aortic stiffness by cardiovascular magnetic resonance following the treatment of severe aortic stenosis by TAVI and surgical AVR
}

Tarique Al Musa ${ }^{1 *}$, Akhlaque Uddin', Timothy A. Fairbairn', Laura E. Dobson', Steven P. Sourbron², Christopher D. Steadman ${ }^{3}$, Manish Motwani ${ }^{1}$, Ananth Kidambi ${ }^{1}$, David P. Ripley ${ }^{1}$, Peter P. Swoboda ${ }^{1}$, Adam K. McDiarmid', Bara Erhayiem', James J. Oliver ${ }^{4}$, Daniel J. Blackman", Sven Plein ${ }^{1}$, Gerald P. McCann ${ }^{3}$ and John P. Greenwood ${ }^{1}$

\begin{abstract}
Background: Aortic stiffness is increasingly used as an independent predictor of adverse cardiovascular outcomes. We sought to compare the impact of transcatheter aortic valve implantation (TAVI) and surgical aortic valve replacement (SAVR) upon aortic vascular function using cardiovascular magnetic resonance (CMR) measurements of aortic distensibility and pulse wave velocity (PW).

Methods and results: A 1.5 T CMR scan was performed pre-operatively and at $6 \mathrm{~m}$ post-intervention in 72 patients (32 TAVI, 40 SAVR; age $76 \pm 8$ years) with high-risk symptomatic severe aortic stenosis. Distensibility of the ascending and descending thoracic aorta and aortic pulse wave velocity were determined at both time points. TAVI and SAVR patients were comparable for gender, blood pressure and left ventricular ejection fraction. The TAVI group were older $(81 \pm 6.3$ vs. $72.8 \pm 7.0$ years, $p<0.05)$ with a higher EuroSCORE II $(5.7 \pm 5.6$ vs. $1.5 \pm 1.0 \%, p<0$. 05). At $6 \mathrm{~m}$, SAVR was associated with a significant decrease in distensibility of the ascending aorta $(1.95 \pm 1.15$ vs. 1 . $\left.57 \pm 0.68 \times 10^{-3} \mathrm{mmHg}^{-1}, p=0.044\right)$ and of the descending thoracic aorta $\left(3.05 \pm 1.12 \mathrm{vs} .2 .66 \pm 1.00 \times 10^{-3} \mathrm{mmHg}^{-1}\right.$, $p=0.018)$, with a significant increase in PWV (6.38 $\left.\pm 4.47 \mathrm{vs} .11 .01 \pm 5.75 \mathrm{~ms}^{-1}, p=0.001\right)$. Following TAVI, there was no change in distensibility of the ascending aorta $\left(1.96 \pm 1.51\right.$ vs. $\left.1.72 \pm 0.78 \times 10^{-3} \mathrm{mmHg}^{-1}, p=0.380\right)$, descending thoracic aorta $\left(2.69 \pm 1.79\right.$ vs. $\left.2.21 \pm 0.79 \times 10^{-3} \mathrm{mmHg}^{-1}, p=0.181\right)$ nor in PWV $\left(8.69 \pm 6.76\right.$ vs. $10.23 \pm 7.88 \mathrm{~ms}^{-1}$, $p=0.301)$ at $6 \mathrm{~m}$.
\end{abstract}

Conclusions: Treatment of symptomatic severe aortic stenosis by SAVR but not TAVI was associated with an increase in aortic stiffness at 6 months. Future work should focus on the prognostic implication of these findings to determine whether improved patient selection and outcomes can be achieved.

Keywords: Aortic stenosis, Transcatheter aortic valve implantation, Aortic valve replacement, Aortic distensibility, Pulse wave velocity, Cardiovascular magnetic resonance

\footnotetext{
* Correspondence: t.a.musa@leeds.ac.uk

${ }^{1}$ Multidisciplinary Cardiovascular Research Centre and The Division of

Cardiovascular and Diabetes Research, Leeds Institute for Cardiovascular and

Metabolic Medicine, University of Leeds, Leeds LS2 9JT, UK

Full list of author information is available at the end of the article
} 


\section{Background}

Aortic valve stenosis is the most common valve disease in the western world [1] with a burden that is excepted to double within the next 50 years. With over 50 years of experience, surgical aortic valve replacement (SAVR) is considered the gold standard therapy for symptomatic severe aortic stenosis. However, many patients are considered too high risk for conventional surgery and transcatheter aortic valve implantation (TAVI) is now an established treatment option for those deemed inoperable [2].

Degenerative aortic stenosis can be viewed as part of a continuum that comprises not only valvular dysfunction but also a reduction in aortic compliance [3] which independently contributes to increased afterload [4] and decreased left ventricular function. Increased aortic stiffening is detrimental to arterio-ventricular coupling and coronary perfusion and is an independent predictor of future cardiovascular events and mortality in the general population, essential hypertension, diabetes mellitus, end stage renal failure and in the elderly [5]. Measurement of aortic stiffness is therefore increasingly used in clinical practise as a prognostic indicator.

Cardiovascular magnetic resonance (CMR) offers a robust, reproducible, non-invasive method of assessing both local and regional properties of the aortic wall [6]. Two standard indices of aortic stiffness can be expressed; aortic distensibility and pulse wave velocity, and there is a strong inverse linear relationship reported between these two measurements $[7,8]$.

The elastic property of the aorta is in part dependent upon the perfusion of the aortic wall via vasa vasorum flow. We hypothesised, based upon the difference in techniques, that more favourable measures of aortic stiffness would be observed following TAVI rather than SAVR. Ultimately, this may herald prognostic implications and guide future patient selection.

The primary aim of this study was to use CMR to serially compare the effects of TAVI and SAVR on aortic stiffness, before and $6 \mathrm{~m}$ after treatment for severe symptomatic aortic stenosis.

\section{Methods}

\section{Study population}

A total of 127 patients were prospectively recruited with severe trileaflet degenerative AS after being referred for either TAVI $(n=77)$ or SAVR $(n=50)$ at the University Hospitals of Leeds and Leicester, UK, between July 2008 and December 2013. Severe AS was classified by transthoracic echocardiography (TTE) as an aortic valve area of $\leq 1.0 \mathrm{~cm}^{2}$. Decision for TAVI was taken by a multidisciplinary heart team in accordance with international guidance. Older, higher-risk (higher EuroSCORE) SAVR patients were preferentially recruited wherever possible to facilitate comparable baseline demographics. Exclusion criteria included any contraindication to CMR as well as patients with a known bicuspid aortic valve or aortopathy. The study was approved by the national ethics committee (NRES Committee Yorkshire \& the Humber-Leeds West, UK), complied with the Declaration of Helsinki and all patients provided written informed consent.

\section{Transcatheter aortic valve implantation}

TAVI was performed under general anaesthesia by highvolume operators with $>5$ years' experience. Either an $18 \mathrm{~F}$ CoreValve Revalving system (CVR, Medtronic, Minneapolis, Minnesota, USA) or an $18 \mathrm{~F}$ or $20 \mathrm{~F} \mathrm{Lotus}^{\mathrm{TM}}$ Aortic Valve system (Boston Scientific Corporation, Natick, USA) were deployed as previously described $[9,10]$.

\section{Surgical aortic valve replacement}

SAVR was performed by standard midline sternotomy with cardiopulmonary bypass and mild hypothermia. Biological or mechanical prostheses of varying sizes were used according to surgical preference; concomitant coronary artery bypass grafting was performed as indicated. No patient underwent aortic root or ascending aortic reconstruction.

\section{CMR protocol}

For each individual patient, identical baseline pre-operative and 6-month post-operative scans were performed on the same 1.5 T MR system (Phillips Intera, Best, The Netherlands or Siemens Avanto Erlangen, Germany).

Multi-slice, multi-phase cine imaging was performed using a standard steady-state free precession (SSFP) pulse sequence in the vertical long-axis, four-chamber, left ventricular outflow tract (LVOT) views, and in the short axis (breath-held, $10 \mathrm{~mm}$ thickness, $0 \mathrm{~mm}$ gap, acquired temporal resolution 30 phases, typical field of view (FOV) $340 \mathrm{~mm}$, acquired spatial resolution $1.88 \times 1.88 \times 10 \mathrm{~mm}$, TR $3.1 \mathrm{~ms}$, TE $1.55 \mathrm{~ms}$ ) to cover the entire left and right ventricles. Through-plane velocity encoded (VENC) phase contrast imaging was performed perpendicular to the aortic valve jet at the aortic sinotubular junction (VENC $250-500 \mathrm{~cm} / \mathrm{s}$, retrospective gating, slice thickness $6 \mathrm{~mm}$, acquired temporal resolution 40 phases, typical FOV $340 \mathrm{~mm}$, acquired spatial resolution $1.56 \times 2.23 \times 6 \mathrm{~mm}$, TR $5 \mathrm{~ms}$, TE $3 \mathrm{~ms}$, breath-held, which for a heart rate of 60 beats per minute was equivalent to $13 \mathrm{~s}$ ).

For aortic distensibility, brachial artery blood pressure was recorded by Dinamap (Critikon, Tampa, USA) immediately prior to high temporal resolution multi-phase SSFP cine imaging (retrospective gating, slice thickness $8 \mathrm{~mm}$, acquired spatial resolution $1.07 \times 1.8 \times 8 \mathrm{~mm}$, acquired temporal resolution 50 phases, TR $3 \mathrm{~ms}$, TE $1.5 \mathrm{~ms}$, breathheld, which for a heart rate of 60 beats per minute was equivalent to $12 \mathrm{~s}$ ) acquired transverse to the ascending and descending thoracic aorta at the level of the pulmonary artery bifurcation. Aortic pulse wave velocity was assessed 
using identical geometric planning with retrospectively gated, through-plane, phase-contrast velocity encoded images (single slice, $8 \mathrm{~mm}$ thick, acquired spatial resolution $2.5 \times 2.67 \times 8 \mathrm{~mm}$, TR $4.6 \mathrm{~ms}$, TE $2.7 \mathrm{~ms}$, acquired temporal resolution 50 phases, typical FOV 350, and VENC $200-500 \mathrm{~cm} / \mathrm{s}$, breath-held, which for a heart rate of 60 beats per minute was equivalent to $13 \mathrm{~s}$ ).

\section{CMR image analysis}

Image analysis was performed in line with international guidance [11], blinded to patient details, using off-line commercially available software (QMass V7.5 and QFlow V7.2, Medis, Leiden, The Netherlands). Standard criteria were employed to delineate LV endocardial and epicardial borders at end-diastole and end-systole for LV mass and volumes. Papillary muscles were excluded from the LV cavity and included within the LV mass for the purpose of analysis. Aortic valve flow indices were quantified using cross-sectional phase contrast images with contouring of the aortic lumen to derive peak forward flow velocity $(\mathrm{m} / \mathrm{s})$, and forward and backward flow volumes (ml), for the calculation of transvalvular pressure gradient and regurgitant fraction (\%).

To derive the aortic distensibility of the ascending and descending thoracic aorta, cross sectional measurements were made by manual planimetry of the endovascularblood pool interface for each phase to determine the maximal and minimal aortic dimensions (Fig. 1a). Aortic distensibility $\left(\mathrm{mmHg}^{-1}\right)$ was calculated using the equation:

Distensibility

$=($ Aortic max lumen area - Aortic min lumen area $)$

/ (Aortic min lumen area $\mathrm{x}$ [Systolic BP - Diastolic BP])

Aortic PWV (m/s) was calculated by dividing the distance separating two locations and the transit time needed to cover this distance [12]. Analysis was performed using a validated software (PMI v0.4, https://github.com/plaresm edima/PMI-0.4-Runtime-CMRLeeds) based on IDL 6.4 (ITT Visual Information Systems, Boulder, USA) [13]. The distance between the ascending and descending aorta was measured manually from the sagittal/oblique cines of the aortic arch (Fig. 1b). Transit time was calculated using the foot-foot delay method from velocity encoded images of the ascending and descending aorta, manually contoured to derive velocity-time curves (Fig. 1c) [14].

\section{Statistical analysis}

Continuous variables are presented as mean \pm SD. Normality was determined by the Shapiro-Wilk test. Frequencies are reported as number (\%). The Student $t$ test and Wilcoxon signed rank test were used for continuous variables, and $\chi 2$ or Fisher's exact test for categorical comparisons. Changes over time were assessed for differences between the treatment groups and clinical variables by twoway repeated measures analysis of variance (ANOVA). Predictors of functional change were evaluated by a stepwise linear regression model with baseline measurements entered as covariate factors. All statistical analyses were performed using PASW software (V.21.0 SPSS, IBM, Chicago, USA); two-sided $p<0.05$ considered statistically significant.

\section{Results}

Seventy-two patients (32 TAVI, 40 SAVR) with paired pre-operative and $6 \mathrm{~m}$ post-operative CMR scans were included for analysis. Reasons for non-completion of the CMR protocol were varied and are depicted in Fig. 2. Baseline characteristics of the study population are shown in Table 1. For both individual groups, key demographic and haemodynamic parameters of the excluded patients were not statistically different to those included for analysis
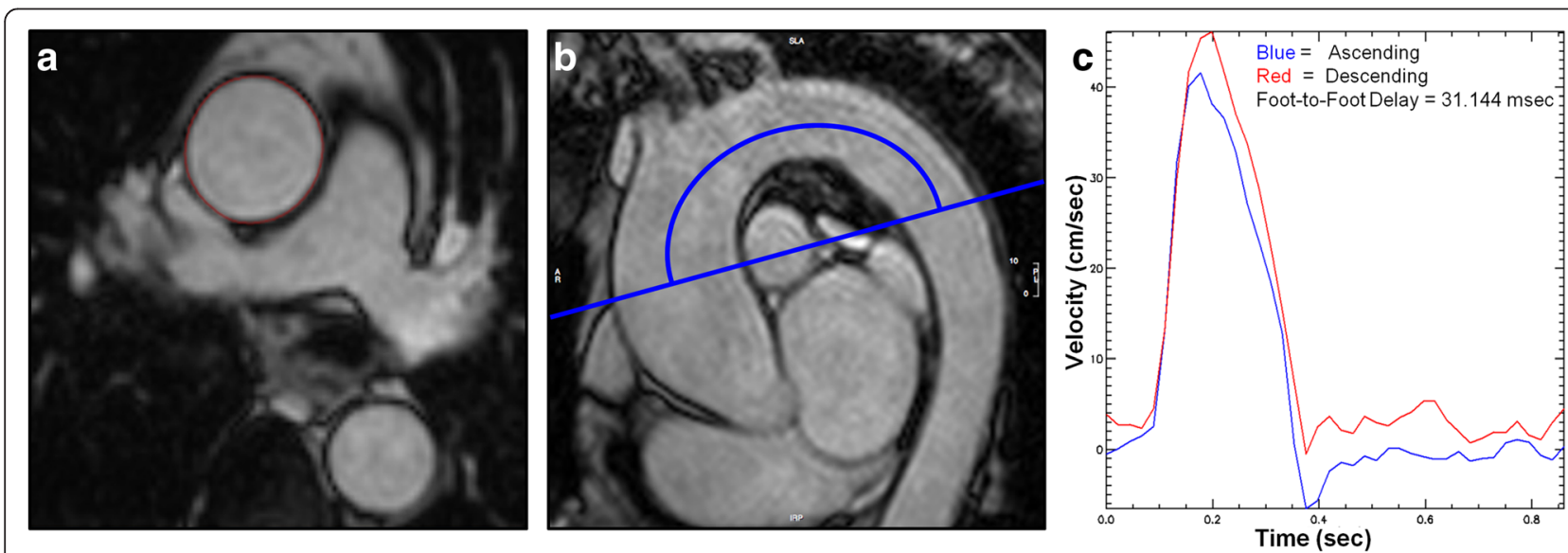

Fig. 1 a Ascending aortic cross-sectional measurements made by manual planimetry of the aortic endovascular-blood pool interface at minimal and maximal distension. $\mathbf{b}$ Sagittal oblique CMR image from which the length of the aortic arch is manually measured. The image is subsequently used to determine site of acquisition of phase contrast cines. c Time-Velocity curve derived using PMI software to calculate foot-foot delay (curves are automatically adjusted/overlaid to accommodate time delay) 


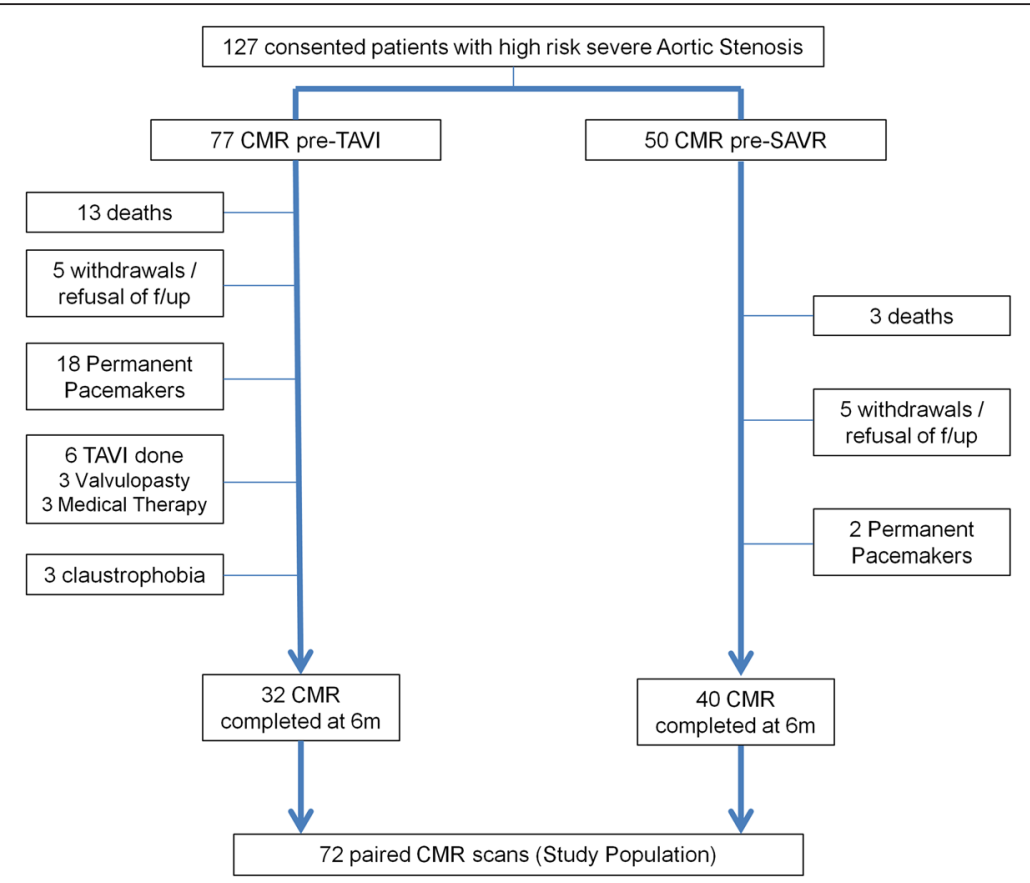

Fig. 2 Patient recruitment pathway

(Table 2), indicating that our study patients were representative of the larger population. The TAVI group were older with a higher predicted 30day mortality risk. The aortic dimensions between the SAVR and TAVI groups were both equivalent and within published normal reference ranges [15] in keeping with our exclusion criteria (Table 1).

\section{Procedural data}

For the TAVI group, 25(78 \%) patients received a Medtronic CoreValve and 7(22\%) a Boston Scientific Lotus valve. The femoral access route was used for 30(94\%) and the subclavian artery for the remaining $2(6 \%)$ patients. Procedural success was $100 \%$ with an average catheterisation time of $159 \pm 48 \mathrm{~min}$, fluoroscopy time of $25 \pm 7 \mathrm{~min}$ and $146 \pm$ $48 \mathrm{ml}$ of contrast administered.

In the surgical group, five patients received a mechanical prosthesis (either Sorin Carbomedics or St Jude's mechanical) and the remaining $35(88 \%)$ a tissue bioprosthesis (Sorin mitroflow, Edwards Perimount Magna, Medtronic Hancock, Hancock II and Mosaic, Vascutek Terumo Aspire). Eleven (28 \%) received concomitant coronary bypass grafting, of which 6 involved use of the left internal mammary artery. For the group as a whole, the average bypass time was $108 \pm 50 \mathrm{~min}$ and average cross clamp time $81 \pm 43 \mathrm{~min}$. The average length of stay in intensive care was $3.5 \pm 2.8$ days.

Aortic valve haemodynamics and LV reverse remodelling Results of the baseline and $6 \mathrm{~m} \mathrm{CMR} \mathrm{scans} \mathrm{are} \mathrm{shown} \mathrm{in}$ Table 3. No significant change in arterial pulse pressure was observed following SAVR $(58.8 \pm 18.6$ vs. $61.4 \pm$ $14.4 \mathrm{mmHg}, p=0.402)$ or TAVI $(63.5 \pm 24.0$ vs. $69.7 \pm$ $20.3 \mathrm{mmHg}, p=0.203)$. There was no significant change in the number of antihypertensive medications used, neither following SAVR $(1.3 \pm 0.8$ vs. $1.4 \pm 0.8, p=0.503)$ or TAVI $(1.2 \pm 1.0$ vs. $1.3 \pm 1.0, p=0.161)$. Reductions in aortic valve pressure gradient, valvuloarterial impedance, LV mass index and end-diastolic volume index were seen $6 \mathrm{~m}$ following both SAVR and TAVI (Table 3).

\section{Aortic stiffness indices}

At baseline there was no difference between the groups in respect to PWV $(p=0.153)$ or distensibility; neither of the ascending $(p=0.838)$ or descending thoracic aortic $(p=0.306)$. Change in indices of aortic stiffness are shown in Fig. 3.

At $6 \mathrm{~m}$, SAVR was associated with a decrease in distensibility of the ascending aorta $(1.95 \pm 1.15$ vs. $1.57 \pm$ $\left.0.68 \times 10^{-3} \mathrm{mmHg}^{-1}, p=0.044\right)$ and of the descending thoracic aorta $\left(3.05 \pm 1.12\right.$ vs. $2.66 \pm 1.00 \times 10^{-3} \mathrm{mmHg}^{-1}$, $p=0.018)$. There was a concomitant increase in PWV observed at $6 \mathrm{~m}\left(6.38 \pm 4.47\right.$ vs. $11.01 \pm 5.75 \mathrm{~ms}^{-1}, p=$ 0.001) (Table 4). These changes were independent of whether or not bypass grafting occurred at the time of valve replacement.

There was no significant change observed in either the distensibility of the ascending aorta $(1.96 \pm 1.51$ vs. 1.72 $\left.\pm 0.78 \times 10^{-3} \mathrm{mmHg}^{-1}, p=0.380\right)$ or of the descending thoracic aorta $\left(2.69 \pm 1.79\right.$ vs. $2.21 \pm 0.79 \times 10^{-3} \mathrm{mmHg}^{-1}$, $p=0.181$ ) following TAVI. Similarly, TAVI was not 
Table 1 Patient characteristics and baseline data

\begin{tabular}{|c|c|c|c|}
\hline Characteristics & $\operatorname{SAVR}(n=40)$ & TAVI $(n=32)$ & $p$ value* \\
\hline Age & $72.8 \pm 7.0$ & $81 \pm 6.3$ & 0.001 \\
\hline Male gender, $n(\%)$ & $31(78)$ & $20(63)$ & 0.151 \\
\hline EuroSCORE II (\%) & $1.53 \pm 1.0$ & $5.66 \pm 5.6$ & 0.001 \\
\hline STS Mortality (\%) & $2.01 \pm 0.6$ & $5.68 \pm 3.8$ & 0.001 \\
\hline $\mathrm{BMI}\left(\mathrm{kgm}^{-2}\right)$ & $27.9 \pm 6.3$ & $26.6 \pm 2.8$ & 0.274 \\
\hline Systolic BP (mmHg) & $131 \pm 23$ & $127 \pm 28$ & 0.696 \\
\hline Diastolic BP (mmHg) & $73 \pm 11$ & $65 \pm 11$ & 0.003 \\
\hline Resting Heart Rate (bpm) & $64 \pm 12$ & $65 \pm 11$ & 0.713 \\
\hline NYHA class & $2.5 \pm 0.6$ & $3 \pm 1.0$ & 0.002 \\
\hline Previous MI, n (\%) & $5(13)$ & $6(19)$ & 0.560 \\
\hline Previous PCl, $n$ (\%) & $1(3)$ & $10(31)$ & 0.001 \\
\hline Previous CABG, $n(\%)$ & $0(0)$ & $12(38)$ & 0.001 \\
\hline Stroke/TIA, $n(\%)$ & $7(18)$ & $4(13)$ & 0.667 \\
\hline $\begin{array}{l}\text { Peripheral vascular } \\
\text { disease, } n(\%)\end{array}$ & $1(3)$ & $6(19)$ & 0.028 \\
\hline Diabetes Mellitus, n (\%) & $4(10)$ & $8(25)$ & 0.125 \\
\hline Hyperlipidaemia, n (\%) & $24(60)$ & $20(63)$ & 0.977 \\
\hline COPD, n (\%) & $4(10)$ & $6(19)$ & 0.358 \\
\hline Atrial Fibrillation, $n(\%)$ & $1(3)$ & $8(25)$ & 0.006 \\
\hline eGFR $\left(\mathrm{ml} / \mathrm{min} / 1.73 \mathrm{~m}^{2}\right)$ & $71.7 \pm 13.3$ & $61.4 \pm 17.1$ & 0.006 \\
\hline $\operatorname{AVA}\left(\mathrm{cm}^{2}\right)$ & $0.90 \pm 0.5$ & $0.62 \pm 0.2$ & 0.002 \\
\hline Mean PG (mmHg) & $43 \pm 15.8$ & $51 \pm 13.7$ & 0.023 \\
\hline LVEF (\%) & $52 \pm 12$ & $52 \pm 13$ & 0.961 \\
\hline $\begin{array}{l}\text { ValvuloArterial } \\
\text { Impedance }\left(Z_{\mathrm{va}}\right)\end{array}$ & $3.88 \pm 0.9$ & $4.06 \pm 1.6$ & 0.982 \\
\hline $\begin{array}{l}\text { Median prosthetic } \\
\text { replacement size }(\mathrm{mm})\end{array}$ & 23 & 27 & 0.001 \\
\hline $\begin{array}{l}\text { Sinuses of Valsalva } \\
\text { dimension indexed } \\
\text { to } B S A\left(\mathrm{~mm} / \mathrm{m}^{2}\right)\end{array}$ & $17.9 \pm 2.2$ & $18.1 \pm 2.1$ & 0.615 \\
\hline $\begin{array}{l}\text { Proximal ascending aortic } \\
\text { dimension indexed } \\
\text { to } B S A\left(\mathrm{~mm} / \mathrm{m}^{2}\right)\end{array}$ & $17.4 \pm 2.8$ & $16.9 \pm 2.8$ & 0.505 \\
\hline
\end{tabular}

Values are mean \pm SD or $n(\%)$

Abbreviations: AVA aortic valve area, CABG coronary artery bypass grafting, eGFR estimated glomerular filtration rate, COPD chronic obstructive pulmonary disease, $M I$ myocardial infarction, MPG mean pressure gradient by transthoracic echo, NYHA New York Health Association, $P C l$ percutaneous coronary intervention, SAVR surgical aortic valve replacement, TAVI transcatheter aortic valve implantation, $Z_{v a}$ valvuloarterial impedance (systolic arterial pressure + mean echocardiographic transvalvular gradient / stroke volume index), LVEF left ventricular ejection fraction, BSA body surface area

${ }^{*} p$ value for comparison between procedure types

associated with any significant change in PWV at $6 \mathrm{~m}$ $\left(8.69 \pm 6.76\right.$ vs. $\left.10.23 \pm 7.88 \mathrm{~ms}^{-1}, p=0.301\right)$ (Fig. 4).

\section{Demographic and procedural factors associated with change in aortic stiffness}

In linear regression analysis, no baseline characteristic (including age, gender, eGFR, surgical risk score or Zva) or procedural variable (including surgical times, CABG and valve type or size) was found to be associated with any index of increased aortic stiffness after SAVR.

\section{Discussion}

Aortic physiology is central to governing the entire cardiovascular network, serving as a conduit and also regulating coronary perfusion and LV performance. Only a limited number of studies have evaluated aortic vascular function following intervention for severe aortic stenosis [16-21]. The use of M-mode transthoracic echocardiography to determine proximal aortic distensibility has been the exclusive method of investigation; none have measured local and regional indices simultaneously and none have sought to compare SAVR directly with TAVI.

Using CMR we have been able to demonstrate that treatment of severe aortic stenosis with SAVR, compared to TAVI, is associated with an increase in aortic stiffness at 6 months independent of baseline characteristics. This was consistently defined by non-invasive measurement of both local indices (ascending and descending thoracic aortic distensibility) and a regional index (aortic arch pulse wave velocity).

The elastic properties of the aorta relate to its inherent histological structure, the influence of the autonomic nervous system and the perfusion of the aortic wall via vasa vasorum flow [16]. In this regard, the fundamental difference in the techniques of SAVR and TAVI could explain our observations.

SAVR involves aortotomy and traumatises aortic wall integrity with destruction of the vasa vasorum. The removal the periaortic fat (containing the vasa vasorum) from the ascending aorta in animal studies has been shown to worsen aortic distensibility acutely due to ischemic medial necrosis and altered fibre composition [22]. In a porcine model, histological analysis of avascular aorta following surgical manipulation revealed abnormal straightening of the elastin and collagen fibers of the outer media, resulting in increased aortic stiffness under a wide range of stresses [23] .

A previous study of 31 patients (mean age 67.2 years) found a significant reduction in ascending aortic distensibility at 7 days following mechanical AVR (from 2.21 to 1.01), with a recovery towards pre-operative levels at 6 months (1.79) [19]. The authors suggested that the aetiology was due to "aortic root stunning" implicating surgical trauma to the aortic wall via cannulation, cooling, clamping, incising and then suturing, all of which disrupts the aortic wall continuity. None of this occurs during a conventional TAVI procedure and this may underscore the findings of our study.

Our study may have missed the early period of aortic root stunning as we did not examine aortic stiffness acutely and thus cannot comment on temporal trends post SAVR. 
Table 2 Comparison of baseline demographics and aortic stiffness between included and excluded TAVI and SAVR patients

\begin{tabular}{|c|c|c|c|c|c|c|}
\hline Parameter & SAVR included & SAVR excluded & $p$ value & TAVI included & TAVI excluded & $p$ value \\
\hline Age (years) & $72.8 \pm 7.0$ & $70.0 \pm 8.4$ & 0.261 & $81 \pm 6.3$ & $80 \pm 7.2$ & 0.593 \\
\hline STS score (\%) & $2.01 \pm 0.6$ & $2.06 \pm 0.9$ & 0.900 & $5.68 \pm 3.8$ & $5.34 \pm 2.8$ & 0.693 \\
\hline EuroSCORE II (\%) & $1.53 \pm 1.0$ & $1.35 \pm 0.56$ & 0.116 & $5.66 \pm 5.6$ & $5.18 \pm 3.4$ & 0.691 \\
\hline Systolic BP (mmHg) & $131 \pm 23$ & $127 \pm 23$ & 0.557 & $127 \pm 28$ & $132 \pm 19$ & 0.524 \\
\hline Previous MI (n (\%)) & $5(13)$ & $1(10)$ & 0.611 & $6(19)$ & $4(15)$ & 0.844 \\
\hline Previous PCI (n (\%)) & $1(3)$ & $2(20)$ & 0.250 & $10(31)$ & $8(31)$ & 0.872 \\
\hline $\begin{array}{l}\text { Peripheral Vascular } \\
\text { Disease }(n(\%))\end{array}$ & $1(3)$ & $1(10)$ & 0.531 & $6(19)$ & $6(23)$ & 0.581 \\
\hline Diabetes Mellitus (n (\%)) & $4(10)$ & $4(40)$ & 0.163 & $8(25)$ & $5(19)$ & 0.721 \\
\hline Hyperlipidaemia, n (\%) & $24(60)$ & $8(80)$ & 0.925 & $20(63)$ & $15(58)$ & 0.998 \\
\hline COPD, $n(\%)$ & $4(10)$ & $1(10)$ & 0.801 & $6(19)$ & $5(19)$ & 0.849 \\
\hline Atrial Fibrillation, $n(\%)$ & $1(3)$ & $3(10)$ & 0.121 & $8(25)$ & $5(19)$ & 0.721 \\
\hline AVA $\left(\mathrm{cm}^{2}\right)$ & $0.90 \pm 0.5$ & $0.67 \pm 0.2$ & 0.195 & $0.62 \pm 0.2$ & $0.62 \pm 0.2$ & 0.941 \\
\hline $\operatorname{AAD}\left(\times 10^{-3} \mathrm{mmHg}^{-1}\right)$ & $1.95 \pm 1.15$ & $2.12 \pm 1.07$ & 0.648 & $1.96 \pm 1.51$ & $1.55 \pm 0.61$ & 0.338 \\
\hline
\end{tabular}

Abbreviations: STS Society of Thoracic Surgeons mortality risk score, AVA aortic valve area, AAD ascending aortic distensibility

However our study does suggest that the significant increase in aortic stiffness persists for at least at 6 months. A decrease in distensibility of the descending thoracic aorta has not previously been reported. This finding suggests the surgical insult affects the aorta more globally, extending beyond the point of local clamp contact.

Interestingly, we found that bypass time, cross clamp time, valve size, valve type and concomitant coronary bypass grafting were not associated with a decline in any of the parameters of aortic stiffness. This suggests the deterioration in aortic stiffness seen at the $6 \mathrm{~m}$ time point is insensitive to modifiable surgical technique.

Progressive fragmentation of aortic elastin occurs throughout adulthood and underlies a reduction in the Windkessel effect of the aorta, elevating pulse pressures for a given stroke volume [24]. A recent CMR study measuring both AD and PWV study in healthy subjects reported that aortic segments stiffen with age, but that after the age of 57 years, the ascending aorta is stiffer than the descending thoracic aorta [25]. We also observed greater distensibility in the descending thoracic

Table 3 Preoperative baseline and 6 month follow-up measurements

\begin{tabular}{|c|c|c|c|c|}
\hline & \multicolumn{2}{|l|}{ SAVR } & \multicolumn{2}{|l|}{ TAVI } \\
\hline & Baseline & 6 months & Baseline & 6 months \\
\hline \multicolumn{5}{|l|}{ Haemodynamics } \\
\hline Heart Rate (bpm) & $64 \pm 12$ & $65 \pm 11$ & $65 \pm 11$ & $66 \pm 15$ \\
\hline Systolic BP (mmHg) & $131 \pm 23$ & $133 \pm 20$ & $127 \pm 28$ & $134 \pm 22$ \\
\hline Number of Medications ${ }^{a}$ & $1.3 \pm 0.8$ & $1.4 \pm 0.8$ & $1.2 \pm 1.0$ & $1.3 \pm 1.0$ \\
\hline Systemic Arterial Compliance ${ }^{b}$ & $0.88 \pm 0.3$ & $0.74 \pm 0.2^{*}$ & $0.81 \pm 0.3$ & $0.71 \pm 0.2$ \\
\hline \multicolumn{5}{|l|}{ Aortic Valve } \\
\hline Peak gradient $(\mathrm{mmHg})^{c}$ & $59 \pm 20$ & $32 \pm 18^{* * *}$ & $54 \pm 14$ & $25 \pm 13^{* * *}$ \\
\hline$Z_{\mathrm{va}}$ & $3.9 \pm 0.9$ & $3.5 \pm 0.8^{*}$ & $4.1 \pm 1.6$ & $3.0 \pm 1.1^{* *}$ \\
\hline \multicolumn{5}{|l|}{ Left Ventricle } \\
\hline Mass Index $\left(\mathrm{g} / \mathrm{m}^{2}\right)$ & $80 \pm 25$ & $65 \pm 16^{* * *}$ & $82 \pm 22$ & $68 \pm 18^{* * *}$ \\
\hline EDVI $\left(\mathrm{ml} / \mathrm{m}^{2}\right)$ & $95 \pm 25$ & $77 \pm 14^{* * *}$ & $95 \pm 25$ & $86 \pm 19^{*}$ \\
\hline $\mathrm{EF}(\%)$ & $52 \pm 12$ & $57 \pm 8^{* *}$ & $52 \pm 13$ & $55 \pm 11$ \\
\hline
\end{tabular}

Abbreviations: $E D V I$ end diastolic volume indexed to body surface area, EF ejection fraction, Zva valvuloarterial impedance

Paired $t$ test to compare baseline and 6 months: ${ }^{*} p<0.05,{ }^{* *} p<0.01,{ }^{* * *} p<0.001$

adefined as any of: ACE inhibitor, angiotensin II receptor antagonist, $\beta$ blocker, spironolactone, doxazosin, hydralazine, amlodipine, felodipine or bendrofluazide

${ }^{b}$ Derived as stroke volume index / pulse pressure

'Derived from CMR assessment 

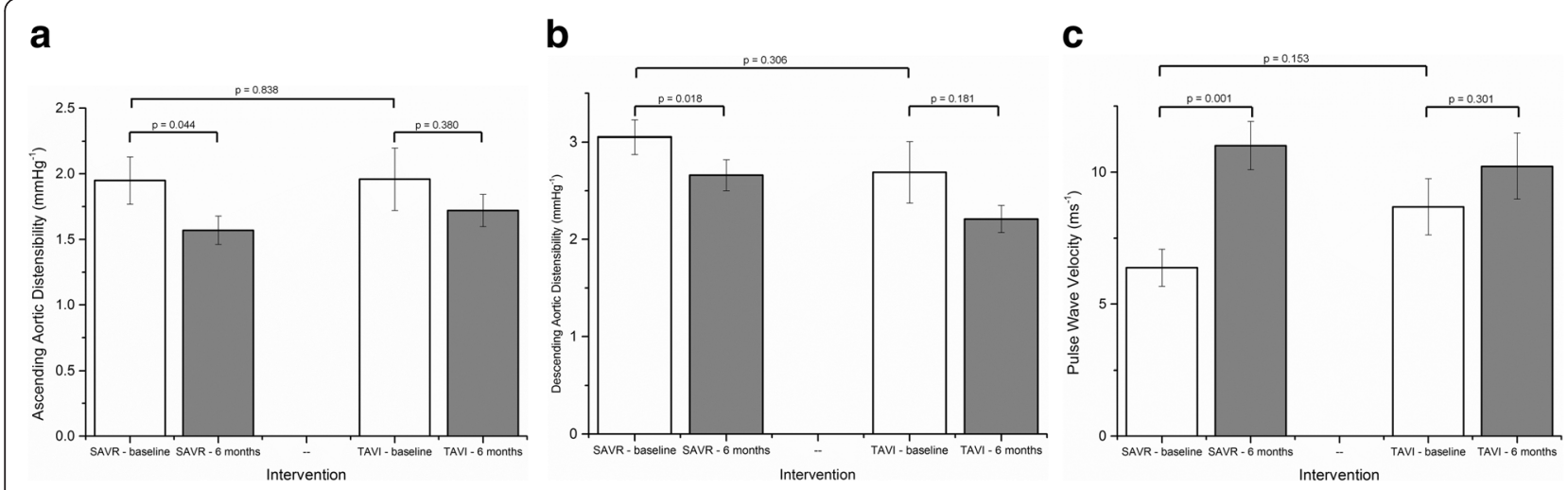

Fig. 3 Bar charts depicting change in indices of aortic stiffness (3 (a) ascending aortic distensibility, 3 (b) descending aortic distensibility, 3 (c) pulse wave velocity) seen pre- and post-SAVR and TAVI (mean and standard error bars)

aorta compared to the ascending aorta in both groups at baseline which reflects this physiological process.

Measures of aortic stiffness, and PWV in particular, exhibit a strong dependence upon age [26] which must be factored into the interpretation of our findings. We have studied two groups with an age difference of approximately 9 years; a reflection of current TAVI implantation criteria. Although the two groups were statistically comparable for PWV at baseline, in absolute terms the PWV values are dissimilar (Fig. 3c); caution is thus required in any clinical interpretation of change in PWV in these two populations. However, the ascending AD of the SAVR group and TAVI group were very similar (1.95 vs. 1.96), yet at 6 months, a statistically significant decline was seen in the SAVR group, but not following TAVI.

It is noteworthy the deleterious effect seen following SAVR was independent of age when entered as a statistical covariate, challenging its potential use in patient selection pre-operatively. Whilst an ascending $\mathrm{AD}$ and PWV of $1.72 \times 10^{-3} \mathrm{mmHg}^{-1}$ and $10.23 \mathrm{~m} / \mathrm{s}$ may be acceptable and expected in patients aged 80 (post-TAVR), worse values of $1.57 \times 10^{-3} \mathrm{mmHg}^{-1}$ and $11.01 \mathrm{~m} / \mathrm{s}$ may not necessarily be acceptable in patients 9 years younger (post-SAVR), undergoing an intervention for prognostic reasons who inherently have a lower surgical risk score.

We and others have shown that lowering of blood pressure can improve aortic stiffness [5, 27, 28]. However in this study, blood pressure and pharmacotherapy were unchanged pre- and post-procedure, suggesting that this was unlikely to account for the difference in impact upon aortic stiffness between TAVI and SAVR. The normal systemic arterial compliance in both groups indicates that baseline haemodynamics were governed predominantly by aortic valve disease without any associated aortic or LV pathology [4]. Following intervention, SAVR was associated with a limited decrease in $\mathrm{Z}_{\mathrm{va}}$ as opposed to TAVI. Given a comparable and important reduction in aortic valve gradient (valvular load), the dampened $Z_{v a}$ response to SAVR likely reflects an increase in arterial load reflecting a mechanical deterioration in aortic function.

The effect of TAVI upon proximal aortic distensibility has been assessed once previously in 30 patients (mean age 79.9 years) using echocardiography 7 days post-procedure [16]. No significant change was observed with an $\mathrm{AD}$ of

Table 4 Change in mean measurements pre- and post SAVR and TAVI

\begin{tabular}{|c|c|c|c|c|c|c|}
\hline & \multicolumn{3}{|l|}{ SAVR } & \multicolumn{3}{|l|}{ TAVI } \\
\hline & Pre & Post & $p$ value* & Pre & Post & $p$ value $^{*}$ \\
\hline Ascending $\mathrm{AD}\left(\times 10^{-3} \mathrm{mmHg}^{-1}\right)$ & $1.95 \pm 1.15$ & $1.57 \pm 0.68$ & 0.044 & $1.96 \pm 1.51$ & $1.72 \pm 0.78$ & 0.380 \\
\hline Descending $\mathrm{AD}\left(\times 10^{-3} \mathrm{mmHg}^{-1}\right)$ & $3.05 \pm 1.12$ & $2.66 \pm 1.00$ & 0.018 & $2.69 \pm 1.79$ & $2.21 \pm 0.79$ & 0.181 \\
\hline Aortic Arch PWV (m/s) & $6.38 \pm 4.47$ & $11.01 \pm 5.75$ & 0.001 & $8.69 \pm 6.76$ & $10.23 \pm 7.88$ & 0.301 \\
\hline Change in AA area ${ }^{* *}\left(\mathrm{~mm}^{2}\right)$ & $99 \pm 54$ & $80 \pm 42$ & 0.032 & $85 \pm 32$ & $91 \pm 38$ & 0.410 \\
\hline Change in DA area*** $\left(\mathrm{mm}^{2}\right)$ & $87 \pm 26$ & $80 \pm 27$ & 0.083 & $73 \pm 28$ & $74 \pm 25$ & 0.916 \\
\hline Pulse pressure (mmHg) & $58 \pm 19$ & $61 \pm 14$ & 0.322 & $63 \pm 24$ & $70 \pm 20$ & 0.150 \\
\hline Length of aortic arch (mm) & $139 \pm 18$ & $134 \pm 20$ & 0.129 & $126 \pm 21$ & $122 \pm 16$ & 0.223 \\
\hline
\end{tabular}

*paired samples $t$-test

** defined as maximal- baseline cross-sectional ascending aortic area

***defined as maximal- baseline cross-sectional descending aortic area 


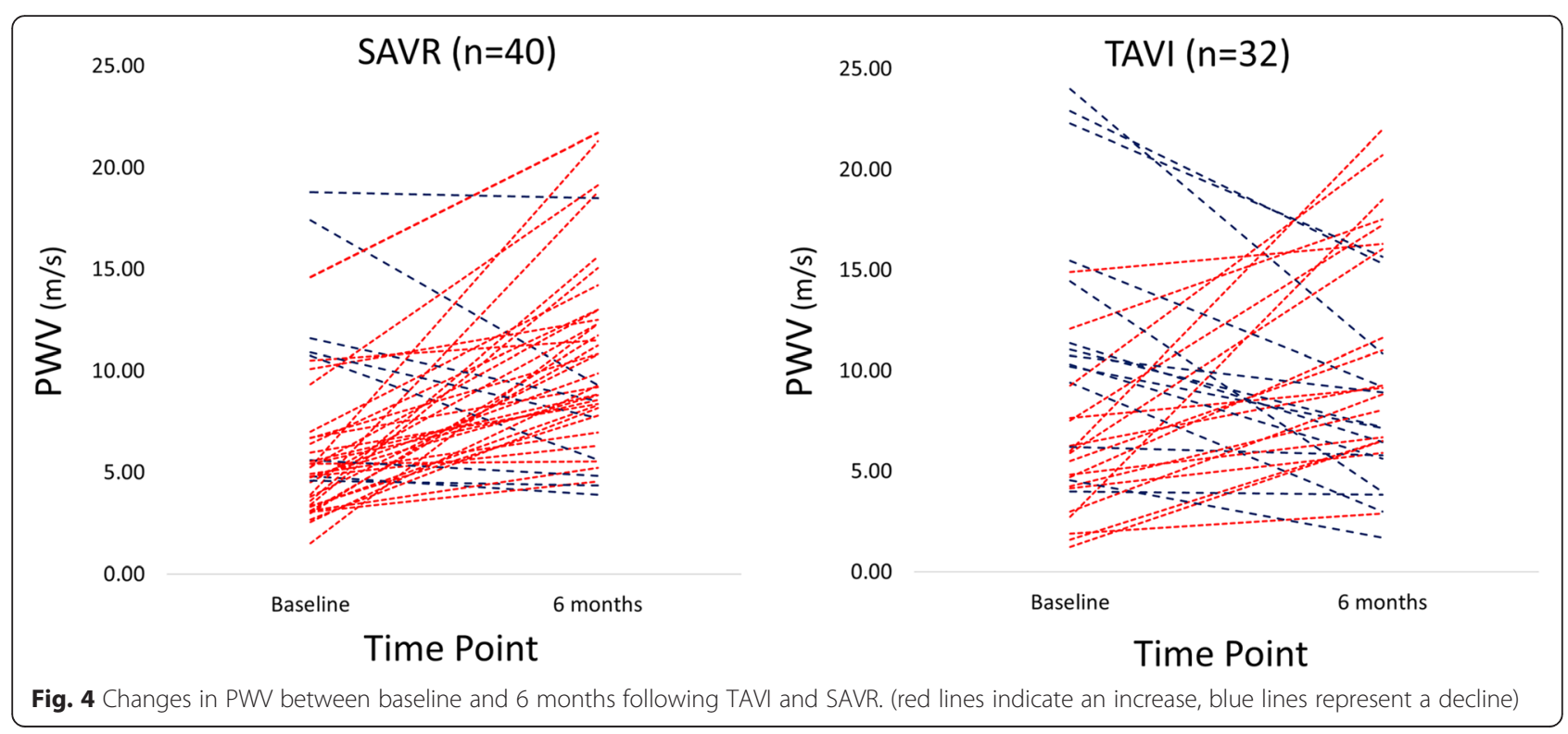

1.89 pre and 2.05 post TAVI. Our study supports these findings and additionally demonstrates preservation of local and regional aortic stiffness at 6 months post-TAVI. Our study indicates the absence of deterioration in aortic stiffness out to 6 months post-TAVI may favour its usage over SAVR in younger patient populations.

The motivation for this study was to investigate whether TAVI or SAVR is more favourable upon aortic stiffness and thus potentially prognosis. It might be expected that our findings would translate into an increased incidence of adverse cardiovascular events in the surgical population. From a meta-analysis of 17 longitudinal studies comprising 15,877 subjects, an increase in aortic PWV by $1 \mathrm{~m} / \mathrm{s}$ corresponded to an age-, sex-, and risk factoradjusted risk increase of $15 \%$ in all-cause mortality [29]. A dramatic increase in PWV was seen following SAVR in our study although our follow-up data of the surgical group extends to an average of 2.8 years with $95 \%(n=38)$ of subjects surviving, such that the numbers are insufficient to make any direct inference.

In the US CoreValve High Risk Study, a higher survival rate at 1 year in patients undergoing TAVI compared directly with SAVR was likely due to more rapid recovery coupled with relatively lower rates of stroke [2]. Our findings are noteworthy in this respect as aortic stiffness may be a contributory factor to this observation. Indeed, in a study of 310 patients aged 50 years or more, lower aortic distensibility was shown to be an independent predictor of all-cause mortality in patients presenting with first-ever acute ischemic stroke [30]. Larger studies with longer follow-up post AVR are required to determine the precise predictive power of aortic stiffness with respect to mortality and morbidity in this setting.

\section{Study limitations}

The main limitation is the attrition of patients who were unable to complete the CMR protocol at 6 months. This was predominantly in the TAVI population who are a very challenging group to study due to age, frailty and comorbidity. Mortality and pacemaker rates were high, but consistent with large international registries. A small number of TAVI patients declined follow up because of deteriorating health and transfer into long-term nursing care. This is one of the largest studies of its kind and patients not studied at $6 \mathrm{~m}$ were not statistically different in demographics to those that were. Nonetheless, the potential for bias cannot be excluded as the sickest patients who withdrew may have had higher post-procedural arterial stiffness and worst outcomes. Furthermore, our final analysed patient groups were relatively small, giving limited power to report 'no difference' in baseline variables such as PWV, thus raising the possibility of Type 1 and Type 2 errors, and transfer bias influencing our final group comparisons. It is possible that our TAVI population, with an average age of 80 years, may have reached near maximal aortic stiffness. Thus TAVI itself may be deleterious or even beneficial to aortic stiffness, but our particular population we have not been able to elucidate this.

The difference in baseline demographics between the groups was unavoidable due to current TAVI implantation criteria. However, our study remains unprecedented, and can be considered a real life reflection, at least of UK national practice [31]. Finally, this study has not assessed patients undergoing isolated on-pump coronary bypass surgery or direct aortic TAVI. 


\section{Conclusion}

In this two centre comparative study using CMR-derived measurements, treatment of symptomatic severe aortic stenosis by SAVR but not TAVI was associated with an increase in aortic stiffness from baseline to $6 \mathrm{~m}$. Given aortic stiffness is a marker of adverse cardiovascular events, future work should focus on the potential prognostic benefit of TAVI over SAVR, particularly in younger agematched populations, as TAVI implantation criteria evolve.

\begin{abstract}
Abbreviations
$A A D$, ascending aortic distensibility; $A D$, aortic distensibility; ANOVA, analysis of variance; AVA, aortic valve area; $\mathrm{BMI}$, body mass index; $\mathrm{BP}$, blood pressure; BSA, body surface area; CABG, coronary artery bypass grafting; CMR, cardiovascular magnetic resonance; COPD, chronic obstructive pulmonary disease; EDVI, end diastolic volume index; eGFR, estimated glomerular filtration rate; FOV, field of view; LV, left ventricle; LVOT, left ventricular outflow tract; MPG, mean pressure gradient; NYHA, New York Heart Association; $\mathrm{PCl}$, percutaneous coronary intervention; PWV, pulse wave velocity; SAVR, surgical aortic valve replacement; SD, standard deviation; SSFP, steady state free precession; STS, Society of Thoracic Surgeons; TAVI, Transcatheter aortic valve implantation; $T E$, echo time; $T R$, repetition time; VENC, velocity encoded; Zva, valvuloarterial impedance
\end{abstract}

\section{Funding}

This study was part-funded by the British Heart Foundation (PG/11/126/ 29321) and also the National Institute for Health Research Leeds Clinical Research Facility. GPM was supported by a NIHR post-doctoral fellowship. The views expressed are those of the author (s) and not necessarily those of the NHS, NIHR or the Department of Health.

\section{Authors' contributions}

JPG conceived and designed the study. TAM, AU, TAF, CDS and LED performed the recruitment of patients and data acquisition. SS and JJO participated in the implementation of the method of MRI image analysis. DB carried out TAVI implantation. TAM, TAF and AU analysed MRI data and interpreted the results. TAM drafted the manuscript. JPG, SP, JJO and GM gave input into data interpretation. MM, AK, DR, PS, AKM and BE were involved in critical and intellectual revision of the article. All authors edited and revised the manuscript. All authors read and approved the final manuscript.

\section{Competing interests}

DB is a proctor for Medtronic CoreValve.

\begin{abstract}
Author details
${ }^{1}$ Multidisciplinary Cardiovascular Research Centre and The Division of Cardiovascular and Diabetes Research, Leeds Institute for Cardiovascular and Metabolic Medicine, University of Leeds, Leeds LS2 9JT, UK. ²Division of Medical Physics, Leeds Institute for Cardiovascular and Metabolic Medicine, University of Leeds, Leeds, UK. ${ }^{3}$ Department of Cardiovascular Sciences, Cardiovascular Research Centre, Cardiovascular Biomedical Research Unit, University of Leicester, National Institute of Health Research (NIHR), Glenfield General Hospital, Leicester, UK. ${ }^{4}$ Leeds Teaching Hospitals NHS Trust, Leeds General Infirmary, Leeds, UK.
\end{abstract}

Received: 8 March 2016 Accepted: 31 May 2016

Published online: 10 June 2016

\section{References}

1. Nkomo VT, Gardin JM, Skelton TN, Gottdiener JS, Scott CG, Enriquez-Sarano M. Burden of valvular heart diseases: a population-based study. Lancet 2006:368(9540):1005-11.

2. Adams DH, Popma JJ, Reardon MJ, Yakubov SJ, Coselli JS, Deeb GM, et al. Transcatheter aortic-valve replacement with a self-expanding prosthesis. N Engl J Med. 2014;370(19):1790-8.

3. Hachicha Z, Dumesnil JG, Pibarot P. Usefulness of the valvuloarterial impedance to predict adverse outcome in asymptomatic aortic stenosis. J Am Coll Cardiol. 2009;54(11):1003-11.
4. Briand M, Dumesnil JG, Kadem L, Tongue AG, Rieu R, Garcia D, et al. Reduced systemic arterial compliance impacts significantly on left ventricular afterload and function in aortic stenosis: implications for diagnosis and treatment. J Am Coll Cardiol. 2005:46(2):291-8.

5. Ripley DP, Negrou K, Oliver JJ, Worthy G, Struthers AD, Plein S, et al. Aortic remodelling following the treatment and regression of hypertensive left ventricular hypertrophy: a cardiovascular magnetic resonance study. Clin Exp Hypertens. 2015;37(4):308-16.

6. Metafratzi ZM, Efremidis SC, Skopelitou AS, De Roos A. The clinical significance of aortic compliance and its assessment with magnetic resonance imaging. J Cardiovasc Magn Reson : off j Soc Cardiovasc Magn Reson. 2002:4(4):481-91.

7. Dogui A, Kachenoura N, Frouin F, Lefort M, De Cesare A, Mousseaux E, et al. Consistency of aortic distensibility and pulse wave velocity estimates with respect to the Bramwell-Hill theoretical model: a cardiovascular magnetic resonance study. J Cardiovasc Magn Reson : off j Soc Cardiovasc Magn Reson. 2011;13:11.

8. Nelson AJ, Worthley SG, Cameron JD, Willoughby SR, Piantadosi C, Carbone A et al. Cardiovascular magnetic resonance-derived aortic distensibility: validation and observed regional differences in the elderly. J Hypertens. 2009:27(3):535-42.

9. Piazza N, Grube E, Gerckens U, den Heijer P, Linke A, Luha O, et al. Procedural and 30-day outcomes following transcatheter aortic valve implantation using the third generation ( $18 \mathrm{Fr}$ ) corevalve revalving system: results from the multicentre, expanded evaluation registry 1-year following CE mark approval. Eurolntervention. 2008;4(2):242-9.

10. Meredith IT, Worthley SG, Whitbourn RJ, Antonis P, Montarello JK, Newcomb AE, et al. Transfemoral aortic valve replacement with the repositionable Lotus Valve System in high surgical risk patients: the REPRISE I study. Eurolntervention. 2014;9(11):1264-70.

11. Schulz-Menger J, Bluemke DA, Bremerich J, Flamm SD, Fogel MA, Friedrich MG et al. Standardized image interpretation and post processing in cardiovascular magnetic resonance: Society for Cardiovascular Magnetic Resonance (SCMR) board of trustees task force on standardized post processing. J Cardiovasc Magn Reson : off j Soc Cardiovasc Magn Reson. 2013;15:35.

12. Oliver JJ, Webb DJ. Noninvasive assessment of arterial stiffness and risk of atherosclerotic events. Arterioscler Thromb Vasc Biol. 2003;23(4):554-66.

13. Huber A, Sourbron S, Klauss V, Schaefer J, Bauner KU, Schweyer M, et al. Magnetic resonance perfusion of the myocardium: semiquantitative and quantitative evaluation in comparison with coronary angiography and fractional flow reserve. Invest Radiol. 2012;47(6):332-8.

14. el Ibrahim SH, Johnson KR, Miller AB, Shaffer JM, White RD. Measuring aortic pulse wave velocity using high-field cardiovascular magnetic resonance: comparison of techniques. J Cardiovasc Magn Reson : off j Soc Cardiovasc Magn Reson. 2010;12(1):26

15. Evangelista A, Flachskampf FA, Erbel R, Antonini-Canterin F, Vlachopoulos C, Rocchi $G$, et al. Echocardiography in aortic diseases: EAE recommendations for clinical practice. Eur J Echocardiogr : j Work Group Echocardiogr Eur Soc Cardiol. 2010;11(8):645-58.

16. Vavuranakis M, Vrachatis DA, Boudoulas H, Papaioannou TG, Moldovan C, Kariori MG, et al. Effect of transcatheter aortic valve implantation on the ascending aorta's elasticity. Clin Res Cardiol. 2012;101(11):895-9.

17. Nemes A, Galema TW, Geleijnse ML, Soliman OI, Yap SC, Anwar AM, et al. Aortic valve replacement for aortic stenosis is associated with improved aortic distensibility at long-term follow-up. Am Heart J. 2007;153(1):147-51.

18. Nemes A, Galema TW, Soliman OI, Bogers AJ, ten Cate FJ, Geleijnse ML. Improved aortic distensibility after aortic homograft root replacement at long-term follow-up. Int J Cardiol. 2009;136(2):216-9.

19. Barbetseas J, Alexopoulos N, Brili S, Aggeli C, Marinakis N, Vlachopoulos C, et al. Changes in aortic root function after valve replacement in patients with aortic stenosis. Int J Cardiol. 2006:110(1):74-9.

20. Melina G, Rajappan K, Amrani M, Khaghani A, Pennell DJ, Yacoub MH. Aortic distensibility after aortic root replacement assessed with cardiovascular magnetic resonance. J Heart Valve Dis. 2002;11(1):67-74. discussion.

21. Schmidtke C, Bechtel J, Hueppe M, Noetzold A, Sievers HH. Size and distensibility of the aortic root and aortic valve function after different techniques of the ross procedure. J Thorac Cardiovasc Surg. 2000;119(5):990-7.

22. Stefanadis C, Vlachopoulos C, Karayannacos P, Boudoulas H, Stratos C, Filippides $T$, et al. Effect of vasa vasorum flow on structure and function of the aorta in experimental animals. Circulation. 1995;91(10):2669-78.

23. Angouras D, Sokolis DP, Dosios T, Kostomitsopoulos N, Boudoulas $H_{\text {, }}$ Skalkeas $\mathrm{G}$, et al. Effect of impaired vasa vasorum flow on the structure and 
mechanics of the thoracic aorta: implications for the pathogenesis of aortic dissection. Eur J Cardiothorac Surg : off j Eur Assoc Cardiothorac Surg. 2000; 17(4):468-73.

24. Cavalcante JL, Lima JA, Redheuil A, Al-Mallah MH. Aortic stiffness: current understanding and future directions. J Am Coll Cardiol. 2011;57(14):1511-22.

25. Devos DG, Rietzschel E, Heyse C, Vandemaele P, Van Bortel L, Babin D, et al. MR pulse wave velocity increases with age faster in the thoracic aorta than in the abdominal aorta. J Magn Reson Imaging : JMRI. 2015;41(3):765-72.

26. Reference Values For Arterial Stiffness C. Determinants of pulse wave velocity in healthy people and in the presence of cardiovascular risk factors: 'establishing normal and reference values'. Eur Heart J. 2010;31(19):2338-50.

27. Asmar R, Benetos A, London G, Hugue C, Weiss Y, Topouchian J, et al. Aortic distensibility in normotensive, untreated and treated hypertensive patients. Blood Press. 1995;4(1):48-54.

28. Asmar RG, Pannier B, Santoni JP, Laurent S, London GM, Levy BI, et al. Reversion of cardiac hypertrophy and reduced arterial compliance after converting enzyme inhibition in essential hypertension. Circulation. 1988; 78(4):941-50.

29. Vlachopoulos C, Aznaouridis K, Stefanadis C. Prediction of cardiovascular events and all-cause mortality with arterial stiffness: a systematic review and meta-analysis. J Am Coll Cardiol. 2010;55(13):1318-27.

30. Biteker M, Ozden T, Dayan A, Tekkesin Al, Misirli CH. Aortic stiffness and plasma brain natriuretic peptide predicts mortality in acute ischemic stroke. Int J Stroke : off j Int Stroke Soc. 2015;10(5):679-85.

31. Moat NE, Ludman P, de Belder MA, Bridgewater B, Cunningham AD, Young $\mathrm{CP}$, et al. Long-term outcomes after transcatheter aortic valve implantation in high-risk patients with severe aortic stenosis: the U.K. TAVI (United Kingdom Transcatheter Aortic Valve Implantation) Registry. J Am Coll Cardiol. 2011;58(20):2130-8.

\section{Submit your next manuscript to BioMed Central and we will help you at every step:}

- We accept pre-submission inquiries

- Our selector tool helps you to find the most relevant journal

- We provide round the clock customer support

- Convenient online submission

- Thorough peer review

- Inclusion in PubMed and all major indexing services

- Maximum visibility for your research

Submit your manuscript at www.biomedcentral.com/submit

) Biomed Central 